\title{
Orbital Cellulitis with Subperiosteal Abscess (with Video)
}

Juan N. Lessing, MD, FACP' and Reza Manesh, MD ${ }^{2}$

'Division of Hospital Medicine, Department of Medicine, University of Colorado School of Medicine, Aurora, CO, USA; ${ }^{2}$ Department of Medicine, Johns Hopkins University, Baltimore, MD, USA.

KEY WORDS: clinical images; orbital cellulitis; subperiosteal abscess; ophthalmoplegia, ocular movement defect; ophthalmology; infectious disease.

$\mathrm{J}$ Gen Intern Med 34(11):2684-6

DOI: $10.1007 / \mathrm{s} 11606-019-05292-0$

(c) Society of General Internal Medicine 2019 underwent orbitotomy and endoscopic sinus surgery. Immediately after surgery, she had resolution of ocular symptoms except mild supraduction limitations at extremes of gaze (see video in supplmentary material). She was discharged with oral clindamycin and ophthalmology follow-up.

Orbital cellulitis is infection of the contents of the orbit. Distinguishing orbital from preseptal cellulitis is critical as orbital cellulitis can threaten vision and life. Orbital cellulitis should be suspected if proptosis, diplopia, pain with eye movement, or ophthalmoplegia are present. ${ }^{1-3}$ Direct extension from sinus infection is the most common source of orbital cellulitis and subperiosteal abscess. ${ }^{1,}{ }^{2,}{ }^{4}$ For both conditions, orbital imaging is necessary for definitive diagnosis. In adults with orbital cellulitis and/or abscess, polymicrobial infection is the rule, usually including anaerobes. ${ }^{4}$ Compared with young children where antibiotics alone may suffice, in adults surgical drainage of abscesses is usually necessary. ${ }^{4-6}$

Received February 7, 2019

Revised June 28, 2019

Accepted August 1, 2019

Published online September 4, 2019 

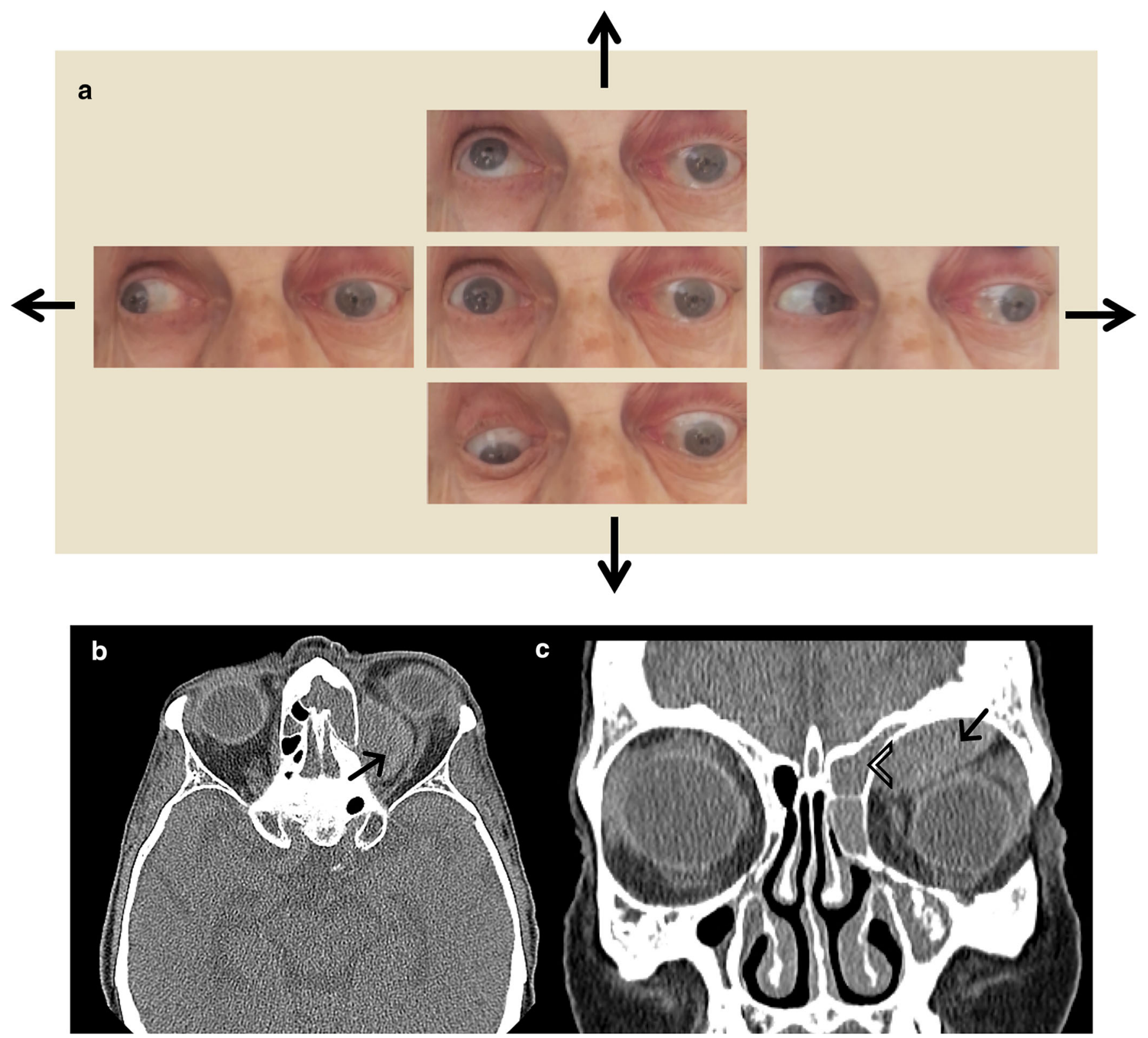

Figure 1 Photographs of ocular movement deficits of the left eye with various eye movements - directions of attempted gaze shown by closest arrow to images (panel a). CT of the orbit without contrast, seen in transverse (panel b) and coronal plane (panel c). Note left eye lenticular $2.8 \times 1.2 \times 2.9 \mathrm{~cm}$ soft-tissue mass (arrow), consistent with a subperiosteal abscess, compressing the superior-rectus and superior-oblique muscles, and complete opacification of numerous sinuses including the left ethmoid sinus (arrowhead).

Acknowledgments: We wish to acknowledge the following contributions: to patient care by Justin A. Edward, MD, Victor Arce Gutierrez, $M D$, Alex C. Stabell, PhD, and Rachel E. Pauley, BSc; technical assistance by Cameron Gordon, Nicholas Mark, MD, and Raul Romero; and editorial recommendations by Susan Hurwitz.

Corresponding Author: Juan N. Lessing, MD, FACP; Division of Hospital Medicine, Department of Medicine University of Colorado School of Medicine, Aurora, CO, USA (e-mail: juan.lessing@ucdenver. $e d u)$.

\section{Compliance with Ethical Standards:}

Conflict of Interest: Drs. Lessing and Manesh have no conflicts of interest. Dr. Lessing has no disclosures. Dr. Manesh is sup- ported by the Jeremiah A. Barondess Fellowship in the Clinical Transaction of the New York Academy of Medicine, in collaboration with the Accreditation Council for Graduate Medical Education (ACGME).

\section{REFERENCES}

1. Sinnott JT 4th, Rodnite JA, Ruland RT. Is this orbital or periorbital cellulitis? Postgrad Med. 1989;85(6):267-9.

2. Armstrong PA, Nichol NM. An eye for trouble: orbital cellulitis. Emerg Med J. 2006;23(12):e66.

3. Givner LB. Periorbital versus orbital cellulitis. Pediatr Infect Dis J. 2002:21(12):1157-8. Review. 
4. Harris GJ. Age as a factor in the bacteriology and response to treatment of subperiosteal abscess of the orbit. Trans Am Ophthalmol Soc. 1993;91:441-516.

5. Lee S, Yen MT. Management of preseptal and orbital cellulitis. Saudi J Ophthalmol. 2011;25(1):21-9. doi: https://doi.org/10.1016/j.sjopt.2010. 10.004
6. Ryan JT, Preciado DA, Bauman N, Pena M, Bose S, Zalzal GH, Choi S. Management of pediatric orbital cellulitis in patients with radiographic findings of subperiosteal abscess. Otolaryngol Head Neck Surg. 2009;140(6):907-11. doi: https://doi.org/10.1016/j.otohns.2009.02.014.

Publisher's Note Springer Nature remains neutral with regard to jurisdictional claims in published maps and institutional affiliations. 